\title{
Herpes and cytomegalovirus esophagitis
}
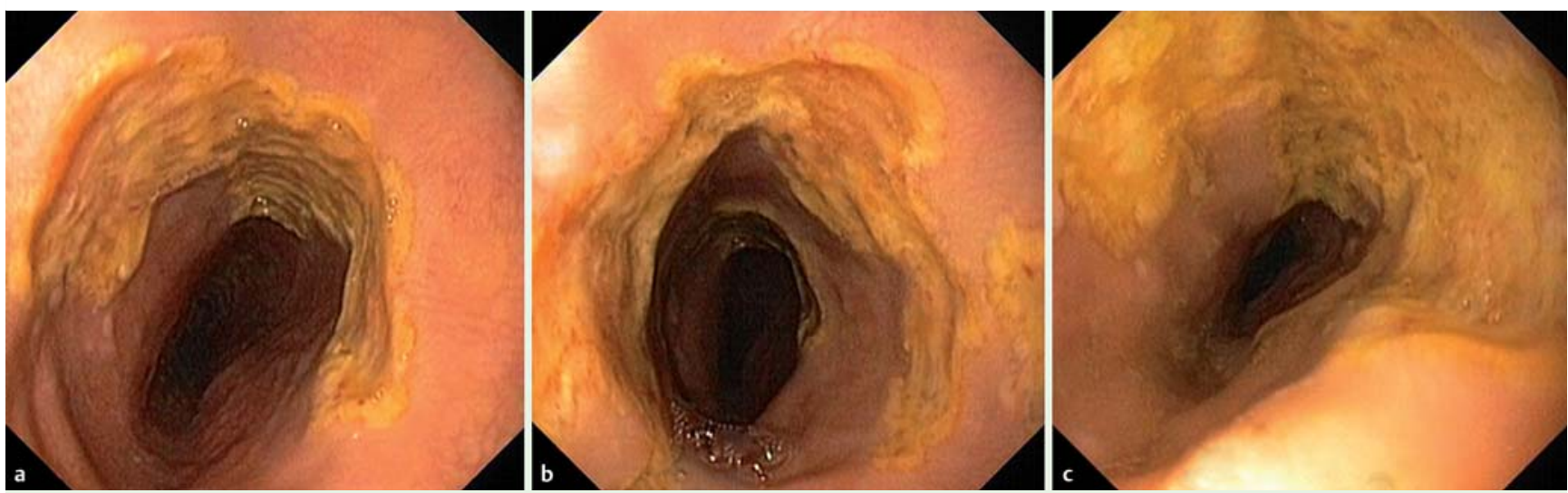

Fig. 1 Upper gastrointestinal endoscopy in a 46-year-old transplant recipient who had recently been treated with high doses of steroids showing ulcerated mucosa in: $\mathbf{a}$ the mid-esophagus; $\mathbf{b}, \mathbf{c}$ the upper esophagus.

A 46-year-old man who underwent a liver transplant in 2001 for fulminant hepatitis of unknown etiology was diagnosed with a liver non-Hodgkin lymphoma (posttransplant lymphoproliferative disease) in 2011. Some months later, he developed an acute hepatocellular rejection that was treated with high doses of steroids.

The patient was admitted because of fever and severe odynophagia that was hindering oral intake. He had multiple painful ulcers on his tongue, palate, and oral mucosa. Upper gastrointestinal endoscopy revealed large superficial, circumferential ulcers with well-defined margins and yellow exudate in the mid and upper esophagus ( $\bullet$ Fig. 1). Biopsies taken from the ulcer base and borders confirmed herpes simplex virus (HSV) and cytomegalovirus $(\mathrm{CMV})$ co-infection ( $\bullet$ Fig. 2). Polymerase chain reaction (PCR) of the esophageal mucosa for HSV and CMV DNA was positive. Human immunodeficiency virus (HIV) serology was negative. The patient's condition rapidly deteriorated and he died from sepsis and liver failure.

Patients with HIV infection, those on chemotherapeutic agents or steroids, and transplant recipients have a high frequency of esophageal infections, although cases of multiple viral infections are very rare [1]. Long-term high-dose corticosteroids may predispose to HSV and CMV infection, although they are much less commonly diagnosed than Candida infections [2].

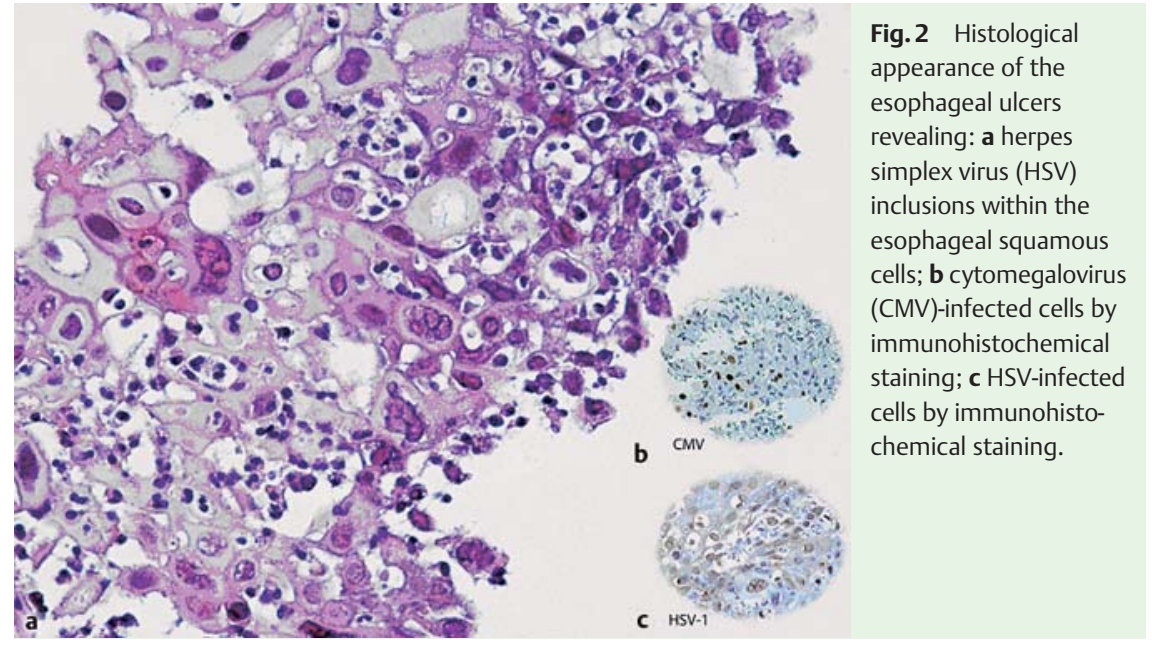

Esophageal ulcers due to CMV are typically large, shallow, solitary or multiple, and located in the mid or distal esophagus [3]. In HSV esophagitis, the morphology depends on the duration of infection [2] and includes nonspecific inflammation, discrete ulcers, coalescent ulcers, and pseudomembranous esophagitis in the mid or lower esophagus. Ulcers due to HSV are typically associated with a yellowish exudate [4]. Three or more biopsies are generally required to rule out viral esophagitis [5]. Co-infection with HSV and CMV has a higher incidence of complications, namely perforation and bleeding [1].

Endoscopy_UCTN_Code_CCL_1AB_2AC_3AZ

\author{
A. Albuquerque ${ }^{1}$, H. Cardoso ${ }^{1,2}$, \\ A. Ribeiro', E. Rios ${ }^{3}$, R. Silva ${ }^{3}$, \\ J. Magalhães ${ }^{3}$, G. Macedo ${ }^{1,2}$ \\ ${ }^{1}$ Gastroenterology Department, Hospital \\ de São João, Porto, Portugal \\ ${ }^{2}$ Gastroenterology Department, Faculty \\ of Medicine of the University of Porto, \\ Portugal \\ ${ }^{3}$ Pathology Department, Hospital São \\ João, Porto, Portugal
}

\section{Competing interests: None}




\section{References}

1 Vodovnik A, Cerar A. Synchronous herpes simplex virus and cytomegalovirus esophagitis. Z Gastroenterol 2000; 38: 491 - 494

2 Baehr PH, McDonald GB. Esophageal infections: risk factors, presentation, diagnosis, and treatment. Gastroenterology 1994; 106: $509-532$

3 Weile J, Streeck B, Muck J et al. Severe cytomegalovirus-associated esophagitis in an immunocompetent patient after short-term steroid therapy. J Clin Microbiol 2009: 3031-3033

4 McBane RD, Gross JB. Herpes esophagitis: Clinical syndrome, endoscopic appearance, and diagnosis in 23 patients. Gastrointest Endosc 1991; 37: 600

5 Srilatha PS, Suvarna N, Gupta A et al. Esophageal ulcer in a HIV-seropositive patient coinfected by herpes simplex and cytomegalovirus. Indian J Pathol Microbiol 2011; 54: $219-220$

\section{Bibliography}

DOI http://dx.doi.org/

10.1055/s-0032-1309385

Endoscopy 2012; 44: E242-E243

(c) Georg Thieme Verlag KG

Stuttgart · New York

ISSN 0013-726X
Corresponding author

A. Albuquerque, MD

Gastroenterology Department

Hospital de São João

Alameda Professor Hernâni Monteiro 4200-319 Porto

Portugal

Fax: +351-225-025766

a.albuquerque.dias@gmail.com 